\title{
Intracranial Subdural Hematoma: a Rare Complication following Spinal Anesthesia: Case Report
}

\author{
Flora Margarida Barra Bisinotto ${ }^{1}$, Roberto Alexandre Dezena ${ }^{2}$, Daniel Capucci Fabri ${ }^{3}$, \\ Tania Mara Vilela Abud ${ }^{4}$, Livia Helena Canno ${ }^{5}$
}

Summary: Bisinotto FMB, Dezena RA, Fabri DC, Abud TMV, Canno LH-Intracranial Subdural Hematoma: a Rare Complication following Spinal Anesthesia: Case Report.

Background and objectives: Intracranial subdural hematoma is a rare complication following spinal anesthesia. The diagnosis is usually difficult because initial symptoms are the same of post-dural puncture headache. The objective was to report a case of early diagnosed subdural hematoma after spinal anesthesia performed with a fine-gauge needle and single puncture.

Case report: 48-year old female patient, ASA I, undergoing spinal anesthesia for surgery to correct urinary incontinence. The spinal anesthesia was performed with 27G Quincke needle and single puncture. There was no unexpected event in the surgery and the patient was discharged. After 48 hours of spinal puncture, the patient reported sudden, strong headache, affecting especially the orbital region, but also the temporal region, with important improvement in dorsal decubitus and followed by two vomiting episodes. A cranial tomography was requested and revealed the presence of an acute left frontotemporoparietal subdural hematoma. A conservative treatment with analgesics, dexamethasone and hydantoin was indicated. After 17 days, the patient had intense headache, followed by dormancy and paresis of right upper limb and speech and behavior disorders. The hematoma was surgically drained. The patient evolved well and without sequelae.

Conclusions: Headache is the most frequent complication after spinal anesthesia and it is considered of benign evolution. In many cases however, it leads to the late or absent diagnosis of potentially fatal conditions, like subdural hematoma. This case describes a rare case of an acute subdural hematoma following spinal anesthesia with fine-gauge needle in a patient without risk factors for bleeding.

Keywords: Hematoma, Subdural, Spinal; Anesthesia, Spinal; Postoperative Complications; Post-Dural Puncture Headache.

(C2012 Elsevier Editora Ltda. All rights reserved.

\section{INTRODUCTION}

Certain complications of lumbar punctures particularly from spinal anesthesia are well-known and documented. That is the case of headache, low back pain, radicular injuries, abscesses and meningitis. However, intracranial subdural hematoma remains an unusual complication with an incidence of $1: 500,000-1,000,000^{1,2}$. The diagnosis is usually difficult because initial symptoms are the same of post-dural puncture headache. The objective of this study was to report a case of subdural hematoma after spinal anesthesia performed with a fine-gauge needle and single puncture, emphasizing that

Received from Universidade Federal do Triângulo Mineiro (UFTM), Brazil.

1. PhD; Professor at Universidade Federal do Triângulo Mineiro (UFTM)

2. PhD; Physician at the Neurosurgery Department of UFTM

3. Anesthesiologist, Hospital São Paulo of the Universidade Federal de São Paulo UNIFESP

4. PhD; Anesthesiologist at UFTM

5. Anesthesiologist of the Hospital Geral Dr Waldemar Alcântara, Hospital Infantil Albert Sabin, and Hospital Geral de Fortaleza

Submitted on: March 13, 2011.

Approved on: May 19, 2011.

Correspondence to:

Dra. Flora Margarida Barra Bisinotto

Praça dos Lírios, 58 Morada das Fontes

38060460 - Uberaba, MG, Brazil

E-mail: flora@mednet.com.br characterizing headache is very important to early diagnosis of this potentially fatal complication.

\section{CASE REPORT}

Female patient, 48 years old, with urinary incontinence diagnosis, was scheduled for surgery to correct this pathology via perineal route. In the preanesthetic evaluation, she had no complaint about anamnesis, presented normal physical and laboratory exams, including coagulogram and platelet count. She was considered as ASA I physical status. Monitoring consisted of pulse oximetry, non invasive blood pressure, cardioscopy and urinary output. Spinal anesthesia was performed, while sitting down, after asepsis with $0.5 \%$ alcoholic chlorhexidine and puncture in the L3-4 interspace with a 27G Quincke needle and single puncture. The anesthetic used was $0.5 \%(15 \mathrm{mg})$ hyperbaric bupivacaine plus $(100 \mu \mathrm{g})$ morphine sulfate. The patient also received $(5 \mathrm{mg})$ midazolam, $(1 \mathrm{~g})$ cefazolin sodium, $(2 \mathrm{~g})$ dipyrone, $(100 \mathrm{mg})$ ketoprofen and (4 mg) ondansetron, intravenously.

The surgery lasted 90 minutes, without unexpected events. In the postoperative period, she was medicated with dipyrone every six hours, antibiotic and ondansetron. The patient was discharged after 36 hours. After 12 hours of discharge (48 hours after spinal puncture), the patient returned to the surgeon complaining about headache and two vomiting episodes. 
The surgeon referred her to evaluation by the anesthesiologist. Then, the patient reported sudden, strong headache, affecting especially the orbital region, but also the temporal region, with important improvement in dorsal decubitus. She did not have headache history. On physical examination in dorsal decubitus, the patient had only faces of pain, without other alterations. She was medicated with hydration, dipyrone and tenoxicam and requested evaluation by a neurologist, due to the unusual characteristic of headache.

Neurological examination was normal, but the patient reported transient lacunar amnesia (from beginning of headache until improvement, after being medicated). A cranial tomography was requested and showed the presence of an acute left frontotemporoparietal subdural hematoma (Figure 1A). On the following day, a magnetic resonance was performed showing extra-axial collection, with mass effect characterized by deletion of grooves between adjacent cortical gyri and deviation of structures of the median line (Figures 1B and 1C). Intracranial arterial magnetic resonance angiography showed no significative abnormalities (Figure 1D). The patient was medicated with analgesics, dexamethasone and hydantoin with important improvement of the clinical picture. The evaluation by the neurologist indicated a conservative treatment. The patient was discharged after using dexamethasone and hydantoin for three days. When she interrupted the dexamethasone use after 17 days, she had intense headache, followed by dormancy and paresis of the right upper limb and speech and behavior disorders. She reported constant headache moderate intensity within this period of 17 days. The hematoma was surgically drained. The patient recovered well and was discharged in two days.

\section{DISCUSSION}

Acute intracranial subdural hematoma is a rare complication following spinal anesthesia, epidural anesthesia when there is an accidental perforation of dura mater or for diagnostic procedures with cerebrospinal fluid (CSF) puncture. It is important due to the fact that it is a potentially fatal complication. The reported case illustrates well that first manifestations can be the same when the patient has a single clinical picture of post-dural puncture headache, which complicates the early diagnosis of intracranial subdural hematoma.

Since the first reports described by Bier at the end of the $19^{\text {th }}$ century, headache is still an unsolved complication of spinal anesthesia, even using finer needles or with blunt tip ${ }^{3}$. The patient is at risk of developing headache whenever the dura mater and arachnoid membranes are punctured. It is still the main complication of spinal blocks and is characterized by worsening in the first 15 minutes after the patient is in the orthostatic position and its improvement within 30 minutes
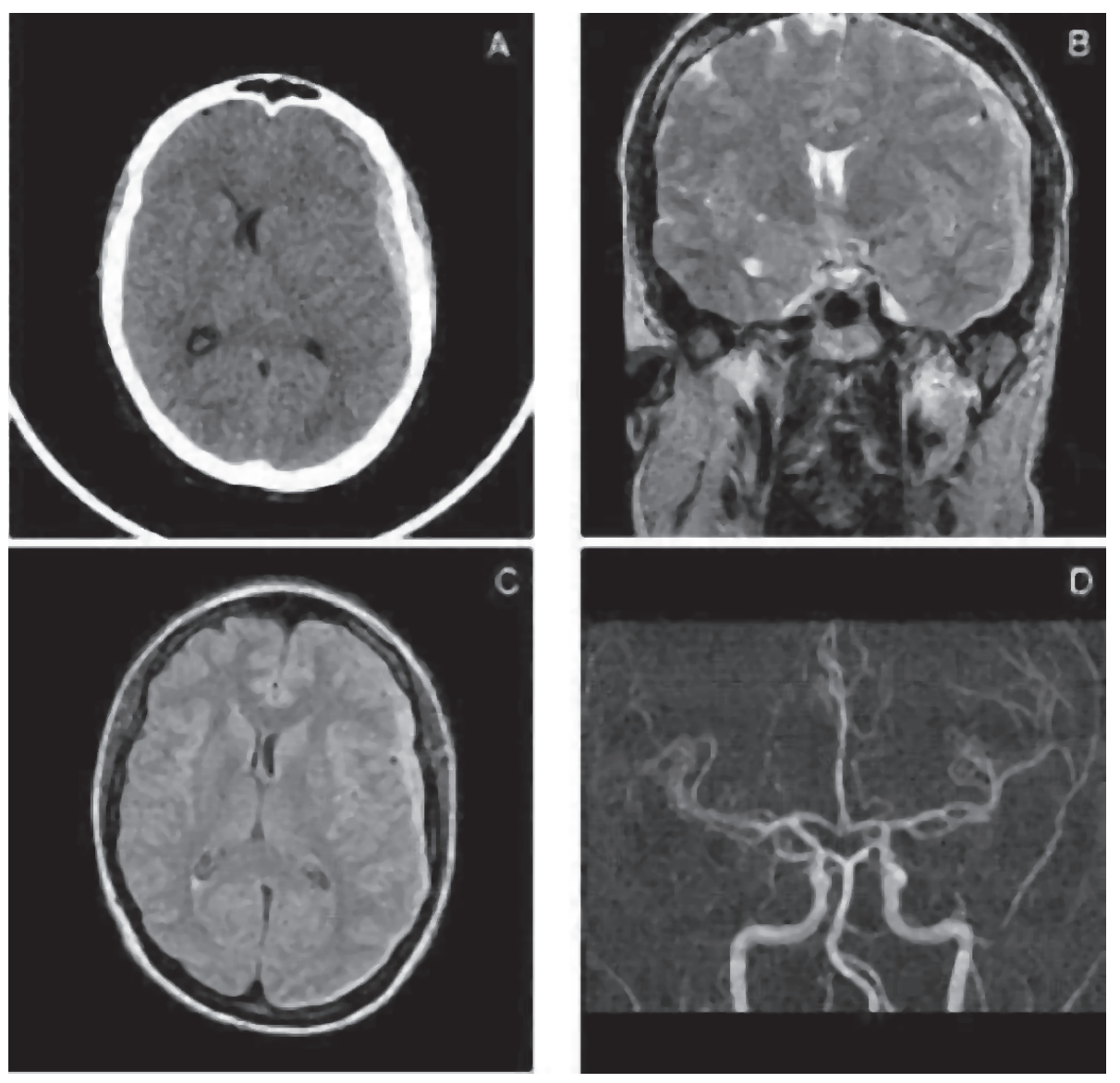

Figure 1 - A: Cranial Tomography. B and C: Cranial Magnetic Resonance. D: Intracranial Arterial Magnetic Resonance Angiography. 
after the patient is in the decubitus position ${ }^{4}$. The definition is important because it enables excluding other algic states, especially migraine ones. Headache usually appears within the first 24-48 hours after puncture, located on the frontal or occipital regions or both, but it can also involve the neck and shoulders region. It is often self-limited and has spontaneous remission after conservative treatment with rest in bed, water replacement and use of drugs that have caffeine, not persisting for over one week, in most cases. Additional symptoms may include neck pain, nausea, vomit, interscapular pain, photophobia, diplopia, dizziness, auditive alteration, visual tarnishing, paralysis of cranial nerves and radicular symptoms in upper extremities ${ }^{5}$.

Although it is not universally accepted, most researchers agree with the "theory of liquor loss" as an explanation for post-dural puncture headache. This theory was already suggested in 1902 and explains that CSF loss through the orifice made by the needle in the dura mater/arachnoid membrane causes a decrease in pressure and volume, leading to a displacement of brain, depending on the severity. It results in the traction of brain structures sensitive to pain.

The speed of CSF loss through perforation of meninges, which can range from 0.08 to $4.5 \mathrm{~mL} . \mathrm{s}^{-1}$, is usually greater than the production speed $\left(0.35 \mathrm{~mL} \cdot \mathrm{min}^{-1}\right)$, especially with needles over $25 G^{6}$. The orifice made in the dura mater may remain open for a period ranging from 14 days to some weeks. The orthostatic headache appears when approximately $10 \%$ of estimated volume of CSF is lost ${ }^{6}$ - and, according to some authors, it would be related to the CSF volume loss and not necessarily to the reduction in CSF pressure ${ }^{7}$. For the brain to remain in its position, upholstered, the volume of CSF must be adequate, otherwise it will succumb to the erect position and tract structures sensitive to pain. A certain quantity of volume may be lost without a consequent reduction of pressure.

An alternative theory for origin of headache says that, with volume loss of CSF, there would be a vis-à-vis compensatory vasodilation, according to the Monro-Kellie doctrine ${ }^{3,6,8}$. This theory is based on constancy of intracranial volume, formed by the sum of brain, CSF and intracranial blood volume. And, as a consequence of the decrease of CSF volume, there would be a compensatory increase in blood volume through venous dilation. This would then be responsible for the headache.

Grant et al. ${ }^{8}$ used magnetic resonance to evaluate CSF loss in patients undergoing CSF puncture. The evaluation of CSF quantity was made before and after puncture. They showed the occurrence of headache in patients with relatively small alteration in CSF volume, confirming this theory. In addition to total brain quantity of CSF, the ventricular volumes, in cortical grooves and in the posterior fossa were also evaluated in the same study. The reduction of CSF volume in cortical grooves was greater when compared with other sites and was responsible for volume reduction of total CSF. This explains why subdural hematoma may occur as a complication of CSF puncture. Boezaart ${ }^{9}$ also demonstrated in pigs the vascular nature of post-dural puncture headache.
When headache persists and looses its posture-dependent characteristic, the occurrence of complications must be considered, such as a subdural hematoma. The same mechanism has been postulated for both post-dural puncture headache and subdural hematoma. The CSF loss through the orifice in the dura mater/arachnoid causes reduction in the volume, which would initially reduce spinal pressure, and more dangerously, intracranial pressure. This alteration in cerebrospinal dynamics results in a caudal movement of medulla and brain, which tracts structures sensitive to pain, dura mater, cranial nerves and veins.

The venous drainage of the brain is made through short venous trunks, almost perpendiculars ${ }^{10}$, called bridging veins, which pass directly from brain to dural sinuses, adherent to internal plank of the skull. Between both points, bridging veins have a straight-line track without tortuosity to enable any possible displacement of brain. Data of electronic microscopy in humans show that veins with thinner walls are located in the subdural space and veins with thicker walls, in the subarachnoid portion ${ }^{11}$. This implies that bridging veins are more fragile in the subdural space than in the subarachnoid space. Traction of those veins may cause their disruption, leading to bleeding. Anteroposterior acceleration or deceleration and/ or traction in those bridging veins may cause disruption in the weakest points in the subdural space. Bjarnhall et al. ${ }^{12}$ reported that disruption of an ascending vein of dura mater may occur while the patient moves. The literature also shows that there are many factors enhancing this mechanism and contributing to the pathogenesis of subdural hematoma after a puncture of subarachnoid space. Those factors include excessive CSF loss due to use of thick needles or with sharp edges to perform spinal anesthesia, as well as multiple attempts or due to inadvertent dural puncture during epidural anesthesia ${ }^{13,14}$; patients with pre-existing neurologic diseases ${ }^{15}$, like the presence of brain aneurysms or arteriovenous malformations, cortical atrophy; alcohool consumption, use in pre or postoperative periods of anticoagulant medications, dehydration and pregnancy. However, using fine needles and/ or with blunt tip (Whitacre) does not eliminate the possibility of occurrence of this complication, as reported here and in other literature cases ${ }^{16,17}$.

Since headache is the most frequent complication and is considered as benign evolution, diagnosis of potentially fatal conditions like subdural hematoma may be made too late or not made at all. In many cases presented in the literature, initial diagnosis was masked by a single diagnosis of headache after spinal anesthesia ${ }^{13,14,18-21}$. According to a review of literature of 21 subdural hematoma cases after inadvertent dura mater puncture, the earliest diagnosis occurred two days after the epidural anesthesia and the latest occurred after 20 weeks ${ }^{21}$. This shows that in the case reported here, diagnosis was made as early as or even earlier, since clinical suspicion occurred after 48 hours of spinal puncture and after some hours of headache onset, confirmed by imaging examination.

The occurrence of neurological symptoms like post-dural puncture headache does not always mean that there was intracranial hemorrhage. The continuous CSF loss leads to 
intracranial hypotension, which generates a neurological syndrome characterized by postural headache that worsens right after the patient is in the orthostatic position and disappears or improves in the decubitus position. The occurrence of subdural hematoma increases intracranial pressure and may be associated with non postural headache, convulsions, hemiplegia and more serious neurological symptoms. The differential diagnosis of neurological symptoms resulting from CSF hypotension and subdural hematoma may be difficult. The change in headache characteristic, from postural to non postural must be an alert.

We recommend the physicians to evaluate the postural characteristic of headache and to follow up diagnosed cases. The possibility of a subdural hematoma must not be excluded, especially if headache is intense and persistent. This situation may lead to cardiac arrest or persistent neurological sequelae. The time elapsed from CSF loss leading to headache and the development of hematoma range from 2 hours to 44 days 21-24. In this aspect, depending on the time of headache onset, its pathophysiological mechanism may be distinct.

This case describes a rare case of, an acute subdural hematoma after spinal anesthesia with a fine needle in a patient without risk factors for bleeding. The hematoma developed early, without an orifice big enough or after prolonged time to enable a great CSF loss, which could explain the beeding by traction of encephalic vessels.

With the frequent use of spinal anesthesia, this rare but catastrophic complication of subdural hematoma must always be remembered. In our opinion, patients who have more risk to have headache, like young women and especially obstetric patients, or those undergoing puncture with thick needle or that undergo several punctures, must be followed up after being discharged. Surgeons and obstetricians must also be aware of the complication, since they are inevitably the first ones to be contacted when the condition sets in. And, since most headache cases are treated without a subsequent investigation, it is believed that the true incidence may be even higher than it has been published ${ }^{21}$.

\section{CONCLUSION}

Severe and progressive headache after spinal anesthesia must be considered an alert to intracranial complication. Anesthesiologists must inform doctors and surgeons about this rare but catastrophic anesthesia complication. A neurological evaluation is recommended to facilitate early diagnosis and a fast intervention to prevent more morbidities as well as mortality. 


\section{REFERENCIAS / REFERENCES}

1. Alilou M, Halelfadl S, Caidi A et al. - Une nouvelle observation d'hematome sous-dural chronique intracrânien au décours d'une rachianesthésie. Ann Fr Anaesth Reanim, 2003;22:560-561.

2. Scott DB, Hibbard BM - Serious nonfatal complications associated with extradural block in obstetric practice. Br J Anaesth, 1990;64:537-541.

3. Imbelloni LE, Sobral MGC, Carneiro ANG - Cefaleia pós-raquianestesia e o desenho das agulhas. Experiência de 5050 casos. Rev Bras Anestesiol, 2001;51(1):43-52

4. Gaiser R - Postdural puncture headache. Cur Opin Anesthesiol, 2006;19:249253.

5. Mokri B - Headaches caused by decreased intracranial pressure: diagnosis and management. Curr Opin Neurol, 2003;16:319-326.

6. Turnbull DR, Shepherd DB - Post-dural puncture headache: pathogenesis, prevention and treatment. Br J Anaesth, 2003:91(5):718-729.

7. Mokri B, Hunter SF, Atkinson JLD et al. - Orthostatic headaches caused by CSF leak but with normal CSF pressures. Neurology, 1998;51:786-790.

8. Grant R, Condon B, Hart I et al. - Changes in intracranial CSF volume after lumbar puncture and their relationship to post-LP headache. J Neurol Neurosurg Psychiatry, 1991;54:440-442.

9. Boezaart AP - Effects of cerebrospinal fluid loss and epidural blood patch on cerebral blood flow in swine. Reg Anesth Pain Med, 2001;26(50);401-406.

10. Han $\mathrm{H}$, Tao W, Zhang $\mathrm{M}$ - The dural entrance of cerebral bridging veins into the superior sagittal sinus: an anatomical comparison between cadavers and digital subtraction angiography. Neuroradiology, 2007;49:169-175.

11. Yamashima T, Friede RL - Why do bridging veins rupture into the virtual subdural space? J Neurol Neurosurg Psychiaty, 1984;47:121-127.

12. Bjarnhall M, Ekseth $\mathrm{K}$, Bostrom $\mathrm{S}$ et al. - Intracranial subdural haematoma: a rare complication following spinal anaesthesia. Acta Anaesthesiol Scand, 1996;40:1249-1251.

13. Kayacan N, Arici G, Kardhi B et al. - Acute subdural haematoma after accidental dural puncture during epidural anaesthesia. Int J Obstet Anesth, 2004; 13:47-49.

14. Amorim JA, Remígio DSCA, Damázio Filho O et al. - Hematoma subdural intracraniano pós-anestesia subaracnóidea: relato de dois casos e revisão de 33 casos da literatura. Rev Bras Anestesiol, 2010;60(6):620-629.

15. Katricioglu K, Aydin O, Ozkalanli MY et al. - Cranial subdural haematoma: a rare complication of spinal anaesthesia. Eur J Anaesthesiol, 2009;26(9):793795.

16. Acharya $\mathrm{R}$ - Chronic subdural haematoma complicating spinal anesthesia. Neurol Sci, 2005;25:348-350.

17. Contais E, Behnamou D, Petit D et al. - Acute subdural hematoma following spinal anesthesia with a very small spinal needle. Anesthesiology, 2000;93(5):1354-1355.

18. Landman UM, Jerome RM, Glass PSA - Subdural hematoma after a traumatic spinal. J Clin Anesth, 2005;17:379-381.

19. Kelsaka E, Sarihasan B, Baris S et al. - Subdural hematoma as a late complocation of spinal anesthesia. J of Surgical Anesthesiol, 2003;15(1):47-49.

20. Bisinotto FMB, Martins Sobrinho J, Augusto CM et al. - Hematoma sub-dural encefálico após anestesia subracnóidea. Rev Bras Anestesiol, 1993;43(3):199-200.

21. Zeidan A, Farhat O, Maaliki H et al. - Does postdural puncture headache left untreated lead to subdural hematoma? Case report and review of the literature. M E J Anesth, 2010;20(4):483-492.

22. Dawley B, Hendrix A - Intracranial subdural hematoma after spinal anesthesia in a parturient. Obstet Gynecol, 2009;113(2):570-572.

23. Baldwin L, Galizia E - Bilateral subdural hematoma: a rare diagnostic dilemma following spinal anesthesia. Anaesth Intensive Care 1993;21:120-121

24. Acharya R, Chhabra SS, Ratra M et al. - Cranial subdural haematoma after spinal anaesthesia. Brit J Anaesth 2001;86(6):893-5. 